\title{
Observations of Amalthea (113) made at the Litchfield Observatory of Hamilton College.
}

A the request of Professor von Oppolzer this planet was followed up as close to the sun as possible, until the observations became too uncertain. In June the weather was not favorable for obtaining more than two positions.

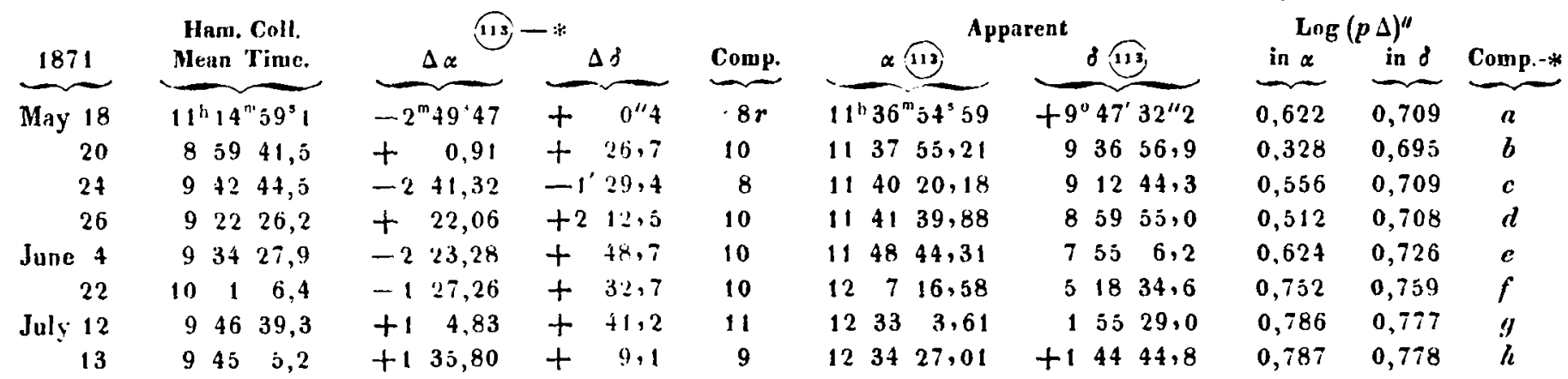

The differences include correction for refraction. On the first day a ring-micrometer was used, on the other days the filarmicrometer with bright wires in a dark field, power 270 . The star positions, for 1871,0, have been assumed as follows:

\begin{tabular}{|c|c|c|c|}
\hline$a$ & $11^{h} 39^{m} 43^{\circ} 45$ & $+9^{\prime \prime} 47^{\prime}$ & $33^{\prime \prime} 4$ \\
\hline \multirow[t]{2}{*}{$b$} & 113753,71 & 936 & 31,7 \\
\hline & $31 \quad 30,81$ & 35 & 51,7 \\
\hline$c$ & 1143 & $9 \quad 14$ & 14,9 \\
\hline$d$ & $11 \$ 17,28$ & 8.57 & 43,8 \\
\hline & 11517,08 & 754 & 18,4 \\
\hline & 12843,42 & 518 & 2,5 \\
\hline & 123158,41 & 154 & 48,2 \\
\hline & 123250,85 & $+1+4$ & 36,2 \\
\hline
\end{tabular}

Struve Cat. Gen. 1347

Dm. $+9^{n}, 2541$, det. by 4 til.-micr. comp. from

Schjell. 4201

Schjell. 4267

$4 A^{\prime}$ Virginis; Mädler's Bradley, and comp. with $\xi$ Virginis Arg. $+7^{\circ}, 2497$ in Bonn Obs. vi.

W. $12^{\mathrm{h}}, 109^{*}$ ), and comp. with Schjell. 4423

Argel. $+2^{\circ}, 2561$ in Bonn Obs. VI.

W. $12^{\mathrm{h}}, 533$.

*) The declination of this star in Weisse's catalogue is $1^{\prime}$ too small; the star is also Lamont 852 .

C. H. F. Peters.

\section{Elemente und Ephemeride der Cassandra (114).}

Fiur den Planeten des 23. Juli, dem der Name Cassa udra beigelegt worden, habe ich aus Beohachtungen von Juli 28, Aug. 8 und 18 die folgenden Elemente erbalten, welche eine spätere Beobachfung, vom 22. August, noch gut darstellen:

Epoche: $18 \% 1$ Jan. o Mitll. Zt. Berlit.

$$
\begin{aligned}
\boldsymbol{M}_{\mathrm{a}} & =118^{\circ} 5^{\prime} 1^{\prime \prime} 84 \\
\pi & =1482923,1 \\
\Omega & =1635332,3 \\
i & =5 \quad 130,05 \\
\varphi & =85132,1 \\
\mu & =817^{\prime \prime} 54 \\
\log a & =0,4249978 .
\end{aligned}
$$

Der Planet ist wahe beim Aphel, und aus den bis dahio gemachten Grössenschätzung ergiebt sich

die miltlere Oppositionshelligkeit $m_{0}=11.1$.

Die Chacornacische Charte to 64. A. wird gegenwärtig die Auffindung erleichtern. Zur genaueren Verfoluung dient die nachstehende Ephemeride.
Ephemeride für $0^{\text {h }}$ mittl. Zt. Berlin.

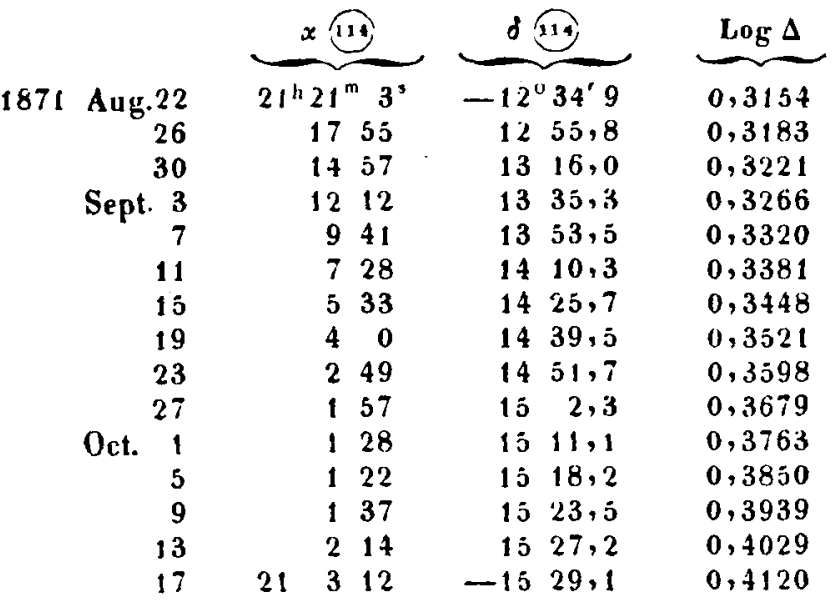

Hamilton College, 1871 Aug. 26. C. H. F. Pelers. 